\title{
Fast Food Consumption and Food Prices: Evidence from Panel Data on 5th and 8th Grade Children
}

\author{
Tamkeen Khan, ${ }^{1}$ Lisa M. Powell, ${ }^{1,2}$ and Roy Wada ${ }^{2}$ \\ ${ }^{1}$ Department of Economics, University of Illinois at Chicago, 601 South Morgan Street, UH725 M/C144, Chicago, IL 60607, USA \\ ${ }^{2}$ Institute for Health Research and Policy, University of Illinois at Chicago, 1747 W. Roosevelt Road, M/C 275, Room 558, Chicago, \\ IL 60608, USA \\ Correspondence should be addressed to Lisa M. Powell, powelll@uic.edu
}

Received 29 August 2011; Revised 14 November 2011; Accepted 20 November 2011

Academic Editor: Douglas Thompson

Copyright () 2012 Tamkeen Khan et al. This is an open access article distributed under the Creative Commons Attribution License, which permits unrestricted use, distribution, and reproduction in any medium, provided the original work is properly cited.

Fast food consumption is a dietary factor associated with higher prevalence of childhood obesity in the United States. The association between food prices and consumption of fast food among 5th and 8th graders was examined using individual-level random effects models utilizing consumption data from the Early Childhood Longitudinal Study, Kindergarten Class of 1998-99 (ECLS-K), price data from American Chamber of Commerce Researchers Association (ACCRA), and contextual outlet density data from Dun and Bradstreet (D\&B). The results found that contextual factors including the price of fast food, median household income, and fast food restaurant outlet densities were significantly associated with fast food consumption patterns among this age group. Overall, a 10\% increase in the price of fast food was associated with 5.7\% lower frequency of weekly fast food consumption. These results suggest that public health policy pricing instruments such as taxes may be effective in reducing consumption of energy-dense foods and possibly reducing the prevalence of overweight and obesity among US children and young adolescents.

\section{Introduction}

The incidence of obesity increased rapidly among children and adolescents in the United States over the last few decades. In 2007-08, obesity prevalence (with body mass index (BMI) greater than or equal to the 95 th percentile of the CDC growth chart) was $19.6 \%$ for children 6 to 11 years of age and $18.1 \%$ for adolescents aged 12 to 19 years [1]. Parallel to the rising prevalence of obesity among children and adolescents, there was a rapid rise in the consumption of, and total energy intake derived from, food away from home, particularly at fast food restaurants $[2,3]$. Consumption of at least one serving of fast food per day was reported by $30.3 \%$ of children and adolescents in 1994-1998 [4]. Fast food restaurants were found to be an important source of food away from home among children aged 2 through 17 years; the percentage of total calories derived from food consumed at fast food restaurants rose from $2 \%$ in the $1977-78$ period to $9 \%$ during the $1994-96$ period [2]. The increased proportion of total caloric intake derived from fast food has been variously attributed to bigger portion sizes, increased convenience, taste, accessibility, and affordability [3, 5-7]. Furthermore, the frequency of fast food consumption was reported to be rising with age among children ages 9 through 19 as their consumption decisions become more independent of parental influences $[6,8]$.

Fast food consumption has been associated with higher total caloric intake, higher total fat and sodium intake, poorer nutrient and vitamin intake, higher BMI, and increased likelihood of obesity [4, 9-13]. An increase in fast food intake during the transition period from adolescence to adulthood was linked to greater weight gain [14]. In addition, obesity itself has been shown to track from childhood to adulthood [15]. Potentially modifiable determinants of childhood eating behaviors and food choices include environmental and contextual factors, such as the availability of healthy food, promotion of appealing and convenient foods, and variations in food prices $[16,17]$. Food prices, in particular, have been shown to be key determinants of consumption [18-23] and therefore may be good candidates for effective policy intervention aimed at improving dietary patterns among children and adolescents. 
A systematic review of time series and household survey studies on price elasticity of demand for food found that consumption of food away from home was more responsive to price changes than any other food category with a $10 \%$ increase in price associated with a $8.1 \%$ reduction in consumption [24]. A limited number of studies on price sensitivity among children and adolescents found mixed evidence on the association between prices and intake of high-fat energy-dense foods. One such study using data from the 1994-1998 Continuing Survey of Food Intakes by Individuals (CSFII) found that higher fast food prices were associated with lower fast food consumption for children aged 2-9 years and adolescents aged $10-18$ years although the association was not statistically significant for the adolescent sample [16]. Using data from a high school cafeteria, another study found that a $10 \%$ increase in the price of higher-fat foods (French fries, cookies, and cheese sauce) and a 25\% reduction in the price of lower-fat foods (fresh fruit, low-fat cookies, low-fat chips, and cereal bars) did not substantially alter revenue, suggesting that consumption patterns shifted towards healthier foods [25]. A vending machine price study found low-fat snack price reductions of 10, 25, and 50 percent corresponded to increased sales of 9,39 , and 93 percent, respectively, among both adolescents and adults [26]. A recent study by Sturm and Datar [27] using a single cross-section of 5th graders found a positive relationship between the price of fast food and intake. However, the authors indicated that this result was not robust and disappeared in alternative specifications potentially due to the correlation between fast food and meat prices in the data.

Linking food price to fast food consumption is important given that a number of recent studies have found statistically significant negative associations between fast food prices and the prevalence of overweight among children and adolescents [28-33]. The link between fast food prices and consumption helps to establish that the observed negative association between fast food prices and obesity operates through fast food consumption and is not due to unobserved confounding factors. Therefore, we expanded on prior studies by using a longitudinal individual-level random effects estimation model, which controls for unobserved individual factors, to examine the relationship between children's fast food consumption and prices of fast food and food at home. Economic contextual factors including median household income and availability of fast food restaurants at the zip code level were included in the analysis to further control for confounding factors. We also examined whether price responsiveness differed across a number of subpopulations.

\section{Methods}

2.1. Data. This study drew on two waves of individuallevel data (5th graders in 2004 and 8th graders in 2007) from the Early Childhood Longitudinal Study, Kindergarten Class of 1998-99 (ECLS-K). Trained evaluators assessed children in their schools, collected information from their parents over the telephone, and contacted teachersand school administrators to complete the questionnaires. Information on the frequency of fast food consumption was self-reported by the children, anthropometric variables such as height and weight were measured by the evaluators, home environment and school characteristics were self-reported by parents, teachers, and school officials. The outcome of interest was child fast food consumption, which was comprised of how many times in the past 7 days the child ate a meal or snack from a fast food restaurant such as McDonald's, Pizza Hut, Burger King, Kentucky Fried Chicken, Taco Bell, Wendy's, and other similar establishments. The responses given by the children were converted from a categorical scale to a numerical scale using midpoints to facilitate analysis.

The contextual data consisted of food prices from the American Chambers of Commerce Researchers Association (ACCRA), fast food outlet density data from Dun and Bradstreet, and median household income from the Census 2000. Food price indices were computed from the ACCRA Cost of Living Index reports, which contain quarterly information on prices in the United States, and which were matched to each child for each year based on the closest zip code match available using the child's home zip code identifier. An index of fast food price was computed using three food items in the ACCRA data, which includes a McDonald's Quarter-Pounder with cheese, a thin-crust regular cheese pizza at Pizza Hut and/or Pizza Inn, and fried chicken (thigh and drumstick) at Kentucky Fried Chicken and/or Church's Fried Chicken. In order to compute the price index of food at home, a basket of grocery items was utilized, which included meats (steak, ground beef, fried chicken, and tuna), fruits and vegetables (potatoes, bananas, lettuce, sweet peas, peaches, and frozen corn), dairy products (half gallon of whole milk, a dozen eggs, margarine, and parmesan cheese), and soft drinks. Both price indices were weighted based on expenditure shares provided by ACCRA derived from the Bureau of Labor Statistics (BLS) Consumer Expenditure Survey. All prices were deflated by BLS Consumer Price Index (CPI; 1982-1984 =1). In addition to the price data, a number of economic contextual variables, including the Census median household income and fast food restaurant density were merged to the restricted geocoded version of ECLS data at the zip code level to account for differences in neighborhood characteristics. The median household income data for each zip code was obtained from the Census 2000. Information on fast food restaurant outlet density was obtained by year and zip code from the Dun and Bradstreet (D\&B) business list data at the primary 8-digit SIC code level for categories of "fast food restaurants and stands" and "chain and independent pizzerias" but not coffee or ice cream shops.

The basic controls consisted of standard individual and household characteristics including age, gender, race (white, African American, Hispanic, other race, and more than one race), mother's highest level of education completed (less than high school, high school, some college, bachelor's degree or more), family income (categories consisting of income below $\$ 20,000, \$ 20,001-\$ 35,000$, $\$ 35,001-$ $\$ 50,000, \$ 50,001-\$ 75,000, \$ 75,001-\$ 100,000$, and $\$ 100,001$ and above), degree of urbanicity (urban, suburban, and rural), and an indicator for the year. Two variables indicating the number of times per week a child ate breakfast and dinner 
with parents were included to account of unobservable characteristics such as the importance the parents place on children's food consumption patterns. Number of hours of television watched per week was included to control for lifestyle behaviors. All data analysis for this project was conducted using STATA 11.0 [34]. This study was approved by the Institutional Review Board at the University of Illinois at Chicago.

2.2. Empirical Model. Children's food consumption may be influenced by a number of economic contextual factors, including food prices. Changes in relative prices of different food products are expected to influence the relative demand for these products. Consumption of fast food will have ownprice effects from fast food prices, and cross-price substitution effects from prices of other foods (such as food at home).

A model of children's fast food consumption of the following form was estimated:

$$
\begin{aligned}
\text { FFCons }_{i s t}= & \delta_{0}+\delta_{1} \text { FFprice }_{s t}+\delta_{2} \text { FHprice }_{s t}+\delta_{3} \text { FFrest }_{s t} \\
& +\delta_{4} \text { MHinc }_{s}+\delta_{5} X_{i t}+\delta_{6} D_{t}+v_{i}+w_{i s t},
\end{aligned}
$$

where FFprice $_{s t}$ and FHprice $_{s t}$ were indices of fast food and food at home prices for geographic area $s$ at time $t$, respectively, for which we also controlled for the average distance of the price match. FFrest ${ }_{s t}$ measured the per capita availability of fast food restaurants for geographic area $s$ at time $t$. MHinc $_{s}$, was the median household income in geographic areas. $X_{i t}$ was a vector of individual and household characteristics for individual $i$ at time $t$. The characteristics in the vector $X_{i t}$ included gender, race/ethnicity, highest level of schooling completed by mother, parental income, urbanicity indicators, number of days per week child ate breakfast with parents, number of days per week child ate dinner with parents, and number of hours per week child watched television. $D_{t}$ was a dummy variable for the survey year. $\delta$ were the parameters to be estimated, $v_{i}$ was the constant individual-specific error, and $w_{i s t}$ was a standard error term.

To take advantage of the longitudinal nature of data, an individual-level random effects model was estimated to provide a weighted average of the between and within estimates where $v_{i t}$ and the independent variables were assumed to be uncorrelated [35]. We tested this assumption based on a Hausman test [36] which indicated that a random effects model was appropriate. Further, we conducted functional form comparisons and determined that a linear form of individual-level random effects model was more appropriate than count data forms. The Poisson goodness-of-fit and the likelihood ratio tests indicated that the Poisson distribution was not suitable for this sample. The point estimates from the linear random effects models were comparable to binomial count models; however, the latter models did not permit the use of clustering and reporting of robust standard error due to the limitation in the statistical software. Further, previous work also examined the distribution of these outcomes and estimated them using linear OLS [37].

Sensitivity analysis was conducted to assess the robustness of the fast food price estimates to exclusions of additional contextual variables. The data showed (not shown in tables) that the frequency of fast food consumption was significantly higher $(P \leq 0.01)$ for children who were male, African American, low-income, and frequent television viewers compared to their counterparts. It is likely that these individuals with greater frequency may be more price sensitive, given that their overall expenditure on fast food would be greater than those with less frequency. Thus, we expanded our analysis to estimate models by various subgroups across gender, race, parental income, and child television usage. Further, given that previous research found that adolescents with body mass index (BMI) in the upper tail of the distribution was more responsive to fast food prices [30], we also estimated models separately by overweight status.

\section{Results and Discussion}

3.1. Descriptive Statistics. The basic summary statistics are shown in Table 1 . The average weekly frequency of fast food consumption by the 5th and 8th graders was roughly 2.5 times in the past week. Among the household characteristics, about half $(50.2 \%)$ of the sample was female. Additionally, about $66.5 \%$ were White, $9.2 \%$ were African American, $15.2 \%$ were Hispanic, $2.2 \%$ defined themselves as multiple races, and $6.9 \%$ were of another race. On average, more than one-half of the children $(63.6 \%)$ had mothers who completed some college or more; about $23.7 \%$ of children had mothers whose highest level of education completed was high school. Approximately, $10.6 \%$ of children lived in families with parental income below $\$ 20,000$, and $38.4 \%$ lived in families with income above $\$ 75,000$. Nearly $67.3 \%$ of the households were from urban residential areas, while $13.4 \%$ were from suburban areas and $19.3 \%$ were from rural areas. Among the economic contextual factors, the average fast food price was $\$ 2.66$ while the average price of food at home was $\$ 1.19$ (based on the 1982-1984 deflated price indices). On average, the median household income at the zip code level was $\$ 47,560$. Finally, there were approximately 3.6 fast food restaurants per 10,000 capita per zip code.

3.2. Longitudinal Regression Analysis. Table 2 presents the regression estimates of childhood fast food consumption using an individual-level random effects model. Higher fast food prices were statistically associated with lower childhood fast food consumption. A one-standard deviation increase in the price of fast food (a $\$ 0.17$ increase) was associated with a reduction in fast food consumption of approximately 0.09 times per week based on the coefficient estimate that a onedollar increase in the price was associated with an approximate decline of 0.53 in the weekly frequency of fast food consumption. Measured as a price elasticity (the percentage change in consumption associated with a one-percent change in price), the estimates corresponded to a price elasticity of -0.57 , suggesting that a $10 \%$ increase in price of fast food was associated with a reduction in weekly consumption by $5.7 \%$, as shown in Table 3 . The results from sensitivity analyses presented in Table 3 show that the relationship between fast food prices and consumption was generally robust to the exclusion of the various other contextual factors. The association of the price of fast food increased slightly by 
TABLE 1: Summary statistics.

\begin{tabular}{|c|c|}
\hline & Mean (SD) \\
\hline \multicolumn{2}{|l|}{ Outcome variable } \\
\hline $\begin{array}{l}\text { Number of times fast food consumed in past } 7 \\
\text { days }\end{array}$ & $2.468(3.955)$ \\
\hline \multicolumn{2}{|l|}{ Price measures } \\
\hline Price of fast food (\$1982-84) & $2.662(0.168)$ \\
\hline Price of food at home (\$1982-84) & $1.185(0.136)$ \\
\hline \multicolumn{2}{|l|}{ Contextual factors } \\
\hline Median household income in $\$ 10,000(\$ 2000)$ & $4.756(1.838)$ \\
\hline Fast food restaurants per 10,000 per capita & $3.598(3.000)$ \\
\hline \multicolumn{2}{|l|}{ Individual, household and local area characteristics } \\
\hline Female & $0.502(0.500)$ \\
\hline Male & $0.498(0.500)$ \\
\hline White & $0.665(0.472)$ \\
\hline African American & $0.092(0.290)$ \\
\hline Hispanic & $0.152(0.359)$ \\
\hline Other & $0.069(0.253)$ \\
\hline More than one race & $0.022(0.147)$ \\
\hline Mother completed less than high school & $0.127(0.332)$ \\
\hline Mother completed at least high school & $0.237(0.426)$ \\
\hline Mother completed at least some college & $0.335(0.472)$ \\
\hline Mother completed bachelor's degree or more & $0.301(0.459)$ \\
\hline Parental income $0-20 \mathrm{~K}$ & $0.106(0.307)$ \\
\hline Parental income $20 \mathrm{~K}-35 \mathrm{~K}$ & $0.152(0.359)$ \\
\hline Parental income $35-50 \mathrm{~K}$ & $0.159(0.366)$ \\
\hline Parental income $50-75 \mathrm{~K}$ & $0.199(0.399)$ \\
\hline Parental income $75-100 \mathrm{~K}$ & $0.168(0.374)$ \\
\hline Parental income $100 \mathrm{~K}+$ & $0.216(0.412)$ \\
\hline 8th grade round $($ year $=2007)$ & $0.513(0.500)$ \\
\hline Household residence urban & $0.673(0.469)$ \\
\hline Household residence suburban & $0.134(0.341)$ \\
\hline Household residence rural & $0.193(0.394)$ \\
\hline Days per week eat breakfast with parents & $3.497(2.399)$ \\
\hline Days per week eat dinner with parents & $5.287(1.752)$ \\
\hline Hours of television child watches weekly & $21.94(15.18)$ \\
\hline
\end{tabular}

Notes: $N=11,700 . \mathrm{SD}=$ standard deviation.

about $20 \%$ (elasticity of -0.69 versus -0.57 ) when all other contextual factors were excluded from the model.

The results for the remaining contextual factors were consistent with expectations. Higher median household income was associated with lower fast food consumption: a $\$ 10,000$ rise in median household income lowered fast food consumption by 0.13 times per week. Greater availability of fast food outlets measured as outlets per capita was associated with higher frequency of fast food consumption. Higher prices of food at home were associated with higher frequency of fast food consumption although the estimate was not statistically significant.

3.3. Subgroup Analysis. Table 4 shows that consumption among males was more responsive to increases in the price of fast food, which was expected given that they were more frequent fast food consumers than were females. We also found greater fast food price sensitivity among children from lowerincome households, but the estimates were not statistically significant. The estimations across ethnicities show that the price of fast food was important and statistically significant for White children but not for African American or Hispanic children despite the fact that minority children consumed fast food more frequently. This suggests minority children's preferences for fast food may be influenced by factors other than food prices. Children who frequently watched television (nine or more hours per week) were found to be more price sensitive than their counterparts. This suggests that higher fast food prices might reduce their consumption to a greater extent, which is important given television watching in general is associated with childhood obesity $[38,39]$ and fast food ads are the most prevalent food ads seen on television by children and adolescents [40]. Finally, we also found stronger price sensitivity among children who were already overweight (BMI greater than or equal to 85th percentile of the CDC growth chart), perhaps because when they consumed from fast food restaurants they purchased more calories. Additionally, there were also significant differences across the subgroups in their response to the other contextual factors. Fast food consumption by children from low-income households was more strongly influenced by zip code level median household income and fast food restaurant outlet density compared to children from high-income households. Furthermore, the protective (reducing) effect of the higher median household income on fast food consumption was 3times-greater for African American and Hispanic minority children than for white children and also greater for more frequent television viewers.

\section{Conclusions}

Policymakers continue to consider a number of potential public health policy interventions aimed at reducing the negative health implications from the increasing rates of obesity prevalence among children and adolescents in the United States. Public health policy may help to reduce obesity prevalence in children and adolescents by utilizing mechanisms that improve diets through the influence of food prices. Children and adolescents often have disposable income and are able to make independent meal selections when food is not purchased for them directly by their parents [3]. In particular, adolescents were estimated to have spent $\$ 159$ billion in 2005 [41]. More specifically, the third highest spending category for this age group after beauty/apparel and videogames/electronics was restaurants $[42,43]$. Since children are less likely to understand the nutritional and health implications of their high caloric consumption patterns, this age group is more likely to be potentially influenced by prices as opposed to health consequences as they may have high rates of time preference [44]. Thus, this study aimed to describe the relationship between fast food and food at home prices and fast food consumption among children in 5th and 8th grade using a nationally representative panel dataset. The results based on longitudinal estimation methods suggested 
TABLE 2: Longitudinal regression estimates for individual level random effects model of the determinants of fast food consumption.

\begin{tabular}{|c|c|c|}
\hline & Consumption of Fast Food & $(\mathrm{SE})$ \\
\hline \multicolumn{3}{|l|}{ Price measures } \\
\hline Price of fast food & $-0.527 * *$ & $(0.241)$ \\
\hline Price of food at home & 0.175 & $(0.401)$ \\
\hline \multicolumn{3}{|l|}{ Contextual factors } \\
\hline Median household income & $-0.131^{* * *}$ & $(0.021)$ \\
\hline Fast food restaurants & $0.025^{* *}$ & $(0.013)$ \\
\hline \multicolumn{3}{|c|}{ Individual, household and local area characteristics } \\
\hline Female & $-0.267 * * *$ & $(0.079)$ \\
\hline African American & $1.932 * * *$ & $(0.022)$ \\
\hline Other & 0.231 & $(0.141)$ \\
\hline Hispanic & $0.627 * * *$ & $(0.139)$ \\
\hline More than one race & 0.331 & $(0.242)$ \\
\hline Mother completed high school & -0.221 & $(0.176)$ \\
\hline Mother completed some college & $-0.350^{* *}$ & $(0.170)$ \\
\hline Mother completed bachelors or more & $-0.625^{* * *}$ & $(0.175)$ \\
\hline Parental income $20-35 \mathrm{~K}$ & $-0.635^{* * *}$ & $(0.207)$ \\
\hline Parental income $35-50 \mathrm{~K}$ & $-0.784^{* * *}$ & $(0.194)$ \\
\hline Parental income $50-75 \mathrm{~K}$ & $-0.825^{* * *}$ & $(0.195)$ \\
\hline Parental income $75-100 \mathrm{~K}$ & $-0.913^{* * *}$ & $(0.192)$ \\
\hline Parental income $100 \mathrm{~K}+$ & $-0.776^{* * *}$ & $(0.192)$ \\
\hline 8 th grade round $($ year $=2007)$ & $-0.787^{* *}$ & $(0.362)$ \\
\hline Household residence is suburban & 0.165 & $(0.123)$ \\
\hline Household residence is rural & -0.085 & $(0.120)$ \\
\hline Days per week eat breakfast with parents & $-0.053^{* * *}$ & $(0.016)$ \\
\hline Days per week eat dinner with parents & $-0.054^{* *}$ & $(0.023)$ \\
\hline Hours of television child watches weekly & $0.014^{* * *}$ & $(0.004)$ \\
\hline
\end{tabular}

Note: regressions include a full set of age dummy variables and average distance between closest ACCRA city and ECLS-K zip code. Standard errors (SE) are reported in parentheses and are robust and clustered at the home zip code level. ${ }^{* *}$ significance at 5\%; ${ }^{* * *}$ significance at $1 \% . N=11,700$.

TABle 3: Longitudinal regression estimates for individual-level random effects model of the determinants of fast food consumption and price elasticity of consumption, by alternate model specifications.

\begin{tabular}{lcc}
\hline & $\begin{array}{c}\text { Fast food price coefficient } \\
\text { estimates }\end{array}$ & Fast food price elasticity \\
\hline Model 1: full specification as shown in Table 3 & $-0.527^{* *}(0.241)$ & $-0.565^{* *}(0.258)$ \\
Model 2: model 1 without median household income & $-0.563^{* *}(0.240)$ & $-0.603^{* *}(.257)$ \\
Model 3: model 1 without fast food restaurant density & $-0.548^{* *}(.243)$ & $-0.586^{* *}(0.260)$ \\
Model 4: model 1 without median household income & $-0.589^{* *}(0.242)$ & $-0.630^{* *}(0.259)$ \\
and fast food restaurant density & $-0.644^{* * *}(0.198)$ & $-0.689^{* * *}(0.211)$ \\
Model 5: model 4 without price of food at home & & \\
\hline
\end{tabular}

Notes: the regression models include all variables shown in Table 2 and those described in the notes of Table 2. Standard errors are reported in parentheses and are robust and clustered at the home zip code level. ${ }^{* *}$ significance at $5 \% ; * * *$ significance at $1 \% . N=11,700$.

that pricing policies in the form of taxes may be an effective tool for reducing fast food consumption. The fast food price elasticity of consumption of -0.57 indicated that this age group was sensitive to price variations such that a ten percent increase in price was associated with a $5.7 \%$ reduction in weekly fast food consumption. This estimate is in the midto lower-range of estimates of price elasticity of demand for food away from home [24].

Earlier studies suggested that pricing mechanisms may have the strongest impact on those individuals who were in the upper tail of the BMI distribution [30]. Consistent with these previous findings, this study found that that price of fast food had a stronger association with consumption among overweight children. We also found a number of subpopulations who were more frequent fast food consumers to be relatively more price sensitive. This suggests that pricing policy instruments such as fast food taxes might be particularly effective in reducing fast food consumption among frequent consumers and those at risk for overweight. This is important given that previous research had showed 
TABLE 4: Longitudinal regression estimates for individual level random effects model of the determinants of fast food consumption, by sub groups.

\begin{tabular}{|c|c|c|c|c|}
\hline & Price of Fast Food & $\begin{array}{c}\text { Price of Food at } \\
\text { Home }\end{array}$ & $\begin{array}{l}\text { Fast Food Restaurant } \\
\text { Outlet Density }\end{array}$ & Median Household Income \\
\hline Full sample & $-0.527^{* *}(0.241)$ & $0.175(0.401)$ & $0.025^{* *}(0.013)$ & $-0.131^{* * *}(0.021)$ \\
\hline \multicolumn{5}{|l|}{ By gender } \\
\hline Female & $0.070(0.345)$ & $-0.783(0.555)$ & $0.022(0.012)$ & $-0.146^{* * *}(0.028)$ \\
\hline Male & $-0.190^{* * *}(0.351)$ & $1.163^{* *}(.056)$ & $0.039(0.026)$ & $-0.108^{* * *}(0.030)$ \\
\hline \multicolumn{5}{|l|}{ By income } \\
\hline $0-35 \mathrm{~K}$ & $-0.627(0.610)$ & $1.223(0.991)$ & $0.074(0.043)$ & $-0.285^{* * *}(0.084)$ \\
\hline $36-75 \mathrm{~K}$ & $-0.407(0.443)$ & $-0.284(0.647)$ & $0.035(0.024)$ & $-0.139 * * *(0.041)$ \\
\hline $75 \mathrm{~K}+$ & $-0.534(0.292)$ & $0.046(0.433)$ & $0.016(0.011)$ & $-0.076^{* * *}(0.019)$ \\
\hline \multicolumn{5}{|l|}{ By weight status } \\
\hline Overweight & $-0.787^{* *}(0.391)$ & $0.944(0.703)$ & $0.080^{* * *}(0.029)$ & $-0.170^{* * *}(0.038)$ \\
\hline Nonoverweight & $-0.397(0.332)$ & $0.083(0.482)$ & $0.007(0.011)$ & $-0.118^{* * *}(0.025)$ \\
\hline \multicolumn{5}{|l|}{ By race } \\
\hline White & $-0.844^{* * *}(0.239)$ & $-0.065(0.368)$ & $0.039^{* * *}(0.012)$ & $-0.081^{* * *}(0.018)$ \\
\hline African American & $0.172(1.389)$ & $-2.360(2.066)$ & $0.063(0.070)$ & $-0.228(0.133)$ \\
\hline Hispanic & $0.073(0.741)$ & $0.893(1.143)$ & $0.022(0.064)$ & $-0.210^{* * *}(0.069)$ \\
\hline \multicolumn{5}{|l|}{ By TV viewing } \\
\hline 9 hours or more per week & $-0.595^{* *}(0.261)$ & $0.229(0.435)$ & $0.028^{* *}(0.014)$ & $-0.140^{* * *}(0.023)$ \\
\hline Less than 9 hours per week & $1.050(0.617)$ & $-0.794(0.870)$ & $-0.028(0.028)$ & $-0.080(0.042)$ \\
\hline
\end{tabular}

Notes: the regression models include all variables shown in Table 2 and those described in the notes of Table 2. Standard errors are reported in parentheses and are robust and clustered at the home zip code level. ${ }^{* *}$ significance at $5 \% ;{ }^{* *}$ significance at $1 \%$.

that adolescents who were overweight were less likely to compensate for their fast food meals by properly adjusting their energy intake downward throughout the remainder of the day [45].

The results from this study were subject to a number of limitations. First, the fast food consumption data were self-reported total number of days per week consumed, not actual amounts of consumption (e.g., caloric intake). Second, the ACCRA price data had number of limitations, which included that the data were only collected in a limited number of cities and metropolitan statistical areas, the data were based on establishment samples that reflect a higher standard of living, and they did not always sample the same cities continuously and hence the data were not fully comparable over time. Third, the outlet density count measures were subject to count error and we were limited to using SIC codes which may have classification errors. Fourth, this study was only able to assess the contextual variables at the zip code level due to data limitations in the availability of more proximate geographic identifiers in the ESLS-K data.

Despite these limitations, the results from the individuallevel random effects model in this paper suggested that higher fast food prices were associated with lower frequency of children's fast food consumption. Therefore, public health policy interventions such as taxes may be effective in reducing consumption of fast food and possibly reducing the prevalence of overweight and obesity among children. Given that the price effects were stronger among children who were male, white, overweight, and frequent television viewers, additional studies based on longitudinal data are needed to develop the evidence base with regard to the potential effectiveness of pricing interventions among various groups of children to help improve food consumption patterns, overall diet, and health outcomes that may possibly translate into healthier outcomes later in adulthood.

\section{Acknowledgments}

Support for this paper was provided by Grant number R01HL096664 from the National Heart, Lung, and Blood Institute and the Robert Wood Johnson Foundation Bridging the Gap ImpacTeen project. The views expressed herein are solely those of the authors and do not reflect the official views or positions of the National Heart, Lung, and Blood Institute, the National Institutes of Health, or the Robert Wood Johnson Foundation.

\section{References}

[1] C. L. Ogden, M. D. Carroll, L. R. Curtin, M. M. Lamb, and K. M. Flegal, "Prevalence of high body mass index in US children and adolescents, 2007-2008," Journal of the American Medical Association, vol. 303, no. 3, pp. 242-249, 2010.

[2] J. F. Guthrie, B. H. Lin, and E. Frazao, "Role of food prepared away from home in the American diet, 1977-78 versus 199496: changes and consequences," Journal of Nutrition Education and Behavior, vol. 34, no. 3, pp. 140-150, 2002.

[3] K. W. Bauer, N. I. Larson, M. C. Nelson, M. Story, and D. Neumark-Sztainer, "Fast food intake among adolescents: secular and longitudinal trends from 1999 to 2004," Preventive Medicine, vol. 48, no. 3, pp. 284-287, 2009. 
[4] S. A. Bowman, S. L. Gortmaker, C. B. Ebbeling, M. A. Pereira, and D. S. Ludwig, "Effects of fast-food consumption on energy intake and diet quality among children in a national household survey," Pediatrics, vol. 113, no. 1, pp. 112-118, 2004.

[5] L. R. Young and M. Nestle, "Portion sizes and obesity: responses of fast-food companies," Journal of Public Health Policy, vol. 28, no. 2, pp. 238-248, 2007.

[6] M. Schmidt, S. G. Affenito, R. Striegel-Moore et al., "Fast-food intake and diet quality in black and white girls: the National Heart, Lung, and Blood Institute growth and health study," Archives of Pediatrics and Adolescent Medicine, vol. 159, no. 7, pp. 626-631, 2005.

[7] S. A. Rydell, L. J. Harnack, J. M. Oakes, M. Story, R. W. Jeffery, and S. A. French, "Why eat at fast-food restaurants: reported reasons among frequent consumers," Journal of the American Dietetic Association, vol. 108, no. 12, pp. 2066-2070, 2008.

[8] E. M. Taveras, C. S. Berkey, S. L. Rifas-Shiman et al., "Association of consumption of fried food away from home with body mass index and diet quality in older children and adolescents," Pediatrics, vol. 116, no. 4, pp. e518-e524, 2005.

[9] O. M. Thompson, C. Ballew, K. Resnicow et al., "Food purchased away from home as a predictor of change in BMI zscore among girls," International Journal of Obesity, vol. 28, no. 2, pp. 282-289, 2004.

[10] S. Paeratakul, D. P. Ferdinand, C. M. Champagne, D. H. Ryan, and G. A. Bray, "Fast-food consumption among US adults and children: dietary and nutrient intake profile," Journal of the American Dietetic Association, vol. 103, no. 10, pp. 1332-1338, 2003.

[11] R. S. Sebastian, C. W. Enns, and J. D. Goldman, "US adolescents and MyPyramid: associations between fast-food consumption and lower likelihood of meeting recommendations," Journal of the American Dietetic Association, vol. 109, no. 2, pp. 226-235, 2009.

[12] R. W. Jeffery, J. Baxter, M. McGuire, and J. Linde, "Are fast food restaurants an environmental risk factor for obesity?" International Journal of Behavioral Nutrition and Physical Activity, vol. 3, p. 2, 2006.

[13] S. A. French, M. Story, D. Neumark-Sztainer, J. A. Fulkerson, and P. Hannan, "Fast food restaurant use among adolescents: associations with nutrient intake, food choices and behavioral and psychosocial variables," International Journal of Obesity, vol. 25, no. 12, pp. 1823-1833, 2001.

[14] H. M. Niemeier, H. A. Raynor, E. E. Lloyd-Richardson, M. L. Rogers, and R. R. Wing, "Fast food consumption and breakfast skipping: predictors of weight gain from adolescence to adulthood in a nationally representative sample," Journal of Adolescent Health, vol. 39, no. 6, pp. 842-849, 2006.

[15] D. S. Freedman, L. K. Khan, M. K. Serdula, W. H. Dietz, S. R. Srinivasan, and G. S. Berenson, "The relation of childhood BMI to adult adiposity: the Bogalusa heart study," Pediatrics, vol. 115 , no. 1, pp. 22-27, 2005.

[16] M. A. Beydoun, L. M. Powell, X. Chen, and Y. Wang, "Food prices are associated with dietary quality, fast food consumption, and body mass index among U.S. children and adolescents," Journal of Nutrition, vol. 141, no. 2, pp. 304-311, 2011.

[17] D. Neumark-Sztainer, M. Story, C. Perry, and M. A. Casey, "Factors influencing food choices of adolescents: findings from focus-group discussions with adolescents," Journal of the American Dietetic Association, vol. 99, no. 8, pp. 929-937, 1999.

[18] R. W. Jeffery, S. A. French, C. Raether, and J. E. Baxter, "An environmental intervention to increase fruit and salad pur- chases in a cafeteria," Preventive Medicine, vol. 23, no. 6, pp. 788-792, 1994.

[19] S. A. French, M. Story, R. W. Jeffery et al., "Pricing strategy to promote fruit and vegetable purchase in high school cafeterias," Journal of the American Dietetic Association, vol. 97, no. 9, pp. 1008-1010, 1997.

[20] S. A. French, R. W. Jeffery, M. Story, P. Hannan, and M. P. Snyder, "A pricing strategy to promote low-fat snack choices through vending machines," American Journal of Public Health, vol. 87, no. 5, pp. 849-851, 1997.

[21] K. B. Horgen and K. D. Brownell, "Comparison of price change and health message interventions in promoting healthy food choices," Health Psychology, vol. 21, no. 5, pp. 505-512, 2002.

[22] L. H. Epstein, K. K. Dearing, E. A. Handley, J. N. Roemmich, and R. A. Paluch, "Relationship of mother and child food purchases as a function of price: a pilot study," Appetite, vol. 47, no. 1, pp. 115-118, 2006.

[23] L. H. Epstein, K. K. Dearing, R. A. Paluch, J. N. Roemmich, and D. Cho, "Price and maternal obesity influence purchasing of low-and high-energy-dense foods," American Journal of Clinical Nutrition, vol. 86, no. 4, pp. 914-922, 2007.

[24] T. Andreyeva, M. W. Long, and K. D. Brownell, "The impact of food prices on consumption: a systematic review of research on the price elasticity of demand for food," American Journal of Public Health, vol. 100, no. 2, pp. 216-222, 2010.

[25] S. A. French, "Pricing effects on food choices," Journal of $\mathrm{Nu}$ trition, vol. 133, no. 3, pp. 841S-843S, 2003.

[26] S. A. French, R. W. Jeffery, M. Story et al., "Pricing and promotion effects on low-fat vending snack purchases: the CHIPS study," American Journal of Public Health, vol. 91, no. 1, pp. 112-117, 2001.

[27] R. Sturm and A. Datar, "Regional price differences and food consumption frequency among elementary school children," Public Health, vol. 125, no. 3, pp. 136-141, 2011.

[28] S. Y. Chou, I. Rashad, and M. Grossman, "Fast-food restaurant advertising on television and its influence on childhood obesity," Journal of Law and Economics, vol. 51, no. 4, pp. 599-618, 2008.

[29] L. M. Powell, M. C. Auld, F. J. Chaloupka, P. M. O’Malley, and L. D. Johnston, "Access to fast food and food prices: relationship with fruit and vegetable consumption and overweight among adolescents," Advances in Health Economics and Health Services Research, vol. 17, pp. 23-48, 2006.

[30] M. C. Auld and L. M. Powell, "Economics of food energy density and adolescent body weight," Economica, vol. 76, no. 304, pp. 719-740, 2009.

[31] A. C. Monheit, J. P. Vistnes, and J. A. Rogowski, "Overweight in adolescents: implications for health expenditures," National Bureau of Economic Research Working Paper 13488, 2007.

[32] L. M. Powell and Y. Bao, "Food prices, access to food outlets and child outcomes," Economics and Human Biology, vol. 7, no. 1, pp. 64-72, 2009.

[33] L. M. Powell, "Fast food costs and adolescent body mass index: evidence from panel data," Journal of Health Economics, vol. 28, no. 5, pp. 963-970, 2009.

[34] StataCorp., "Stata Statistical Software," Release 11. College Station, Tex, USA: StataCorp LP, 2009.

[35] J. M. Wooldridge, Econometric Analysis of Cross Section and Panel Data, MIT Press, Cambridge, Mass, USA, 2002.

[36] M. E. Schaffer and S. Stillman, "Xtoverid: stata module to calculate tests of overidentifying restrictions after xtreg, xtivreg, 
xtivreg2 and xthtaylor," 2010, http://ideas.repec.org/c/boc/ bocode/s456779.html.

[37] T. Andreyeva, I. R. Kelly, and J. L. Harris, "Exposure to food advertising on television: associations with children's fast food and soft drink consumption and obesity," Economics and Human Biology, vol. 9, no. 3, pp. 221-233, 2011.

[38] S. L. Gortmaker, A. Must, A. M. Sobol, K. Peterson, G. A. Colditz, and W. H. Dietz, "Television viewing as a cause of increasing obesity among children in the United States, 19861990," Archives of Pediatrics and Adolescent Medicine, vol. 150, no. 4, pp. 356-362, 1996.

[39] T. N. Robinson, "Reducing children's television viewing to prevent obesity: a randomized controlled trial," Journal of the American Medical Association, vol. 282, no. 16, pp. 1561-1567, 1999.

[40] L. M. Powell, G. Szczypka, and F. J. Chaloupka, "Trends in exposure to television food advertisements among children and adolescents in the United States," Archives of Pediatrics and Adolescent Medicine, vol. 164, no. 9, pp. 794-802, 2010.

[41] Teenage Research Unlimited. TRU projects teens will spend $\$ 159$ billion in 2005. 2005.

[42] Marketing Charts. Teen Spending Shifts To Value; Electronics Hold Firm, 2009, http://www.marketingcharts.com/topics/ behavioral-marketing/teen-spending-shifts-to-value-electronics-hold-firm-9918/.

[43] M. Klein, “Teen green-teenage spending," 1998, http://findarticles.com/p/articles/mi_m4021/is_n2_v20/ai_20302970/.

[44] M. Story, D. Neumark-Sztainer, and S. French, "Individual and environmental influences on adolescent eating behaviors," Journal of the American Dietetic Association, vol. 102, no. 3, pp. S40-S51, 2002.

[45] C. B. Ebbeling, K. B. Sinclair, M. A. Pereira, E. Garcia-Lago, H. A. Feldman, and D. S. Ludwig, "Compensation for energy intake from fast food among overweight and lean adolescents," Journal of the American Medical Association, vol. 291, no. 23, pp. 2828-2833, 2004. 


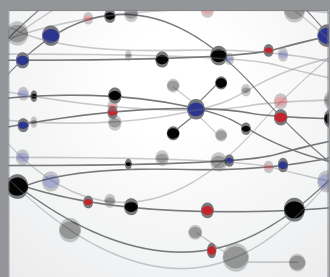

The Scientific World Journal


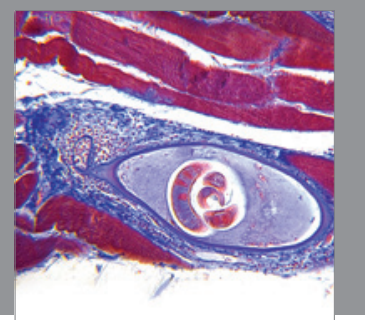

Gastroenterology

Research and Practice
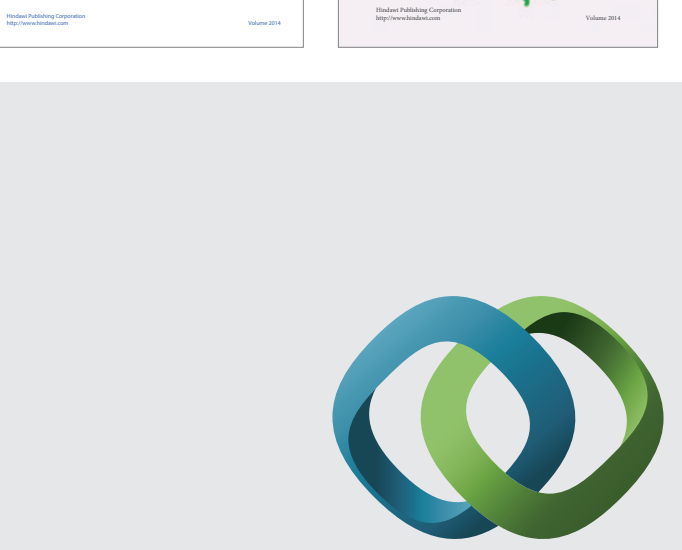

\section{Hindawi}

Submit your manuscripts at

http://www.hindawi.com
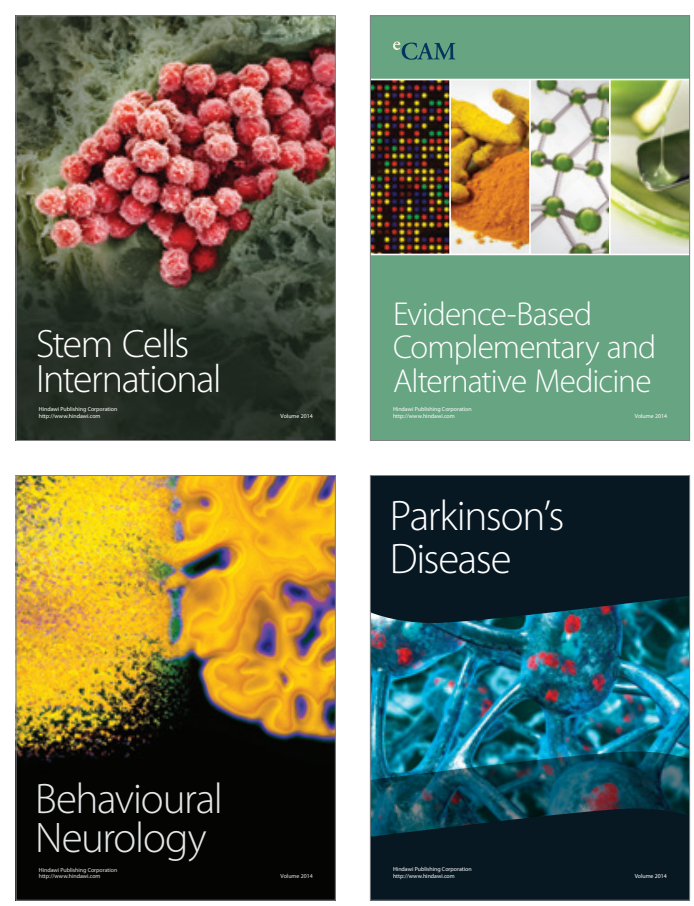



Journal of
Diabetes Research

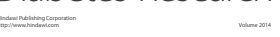



Disease Markers
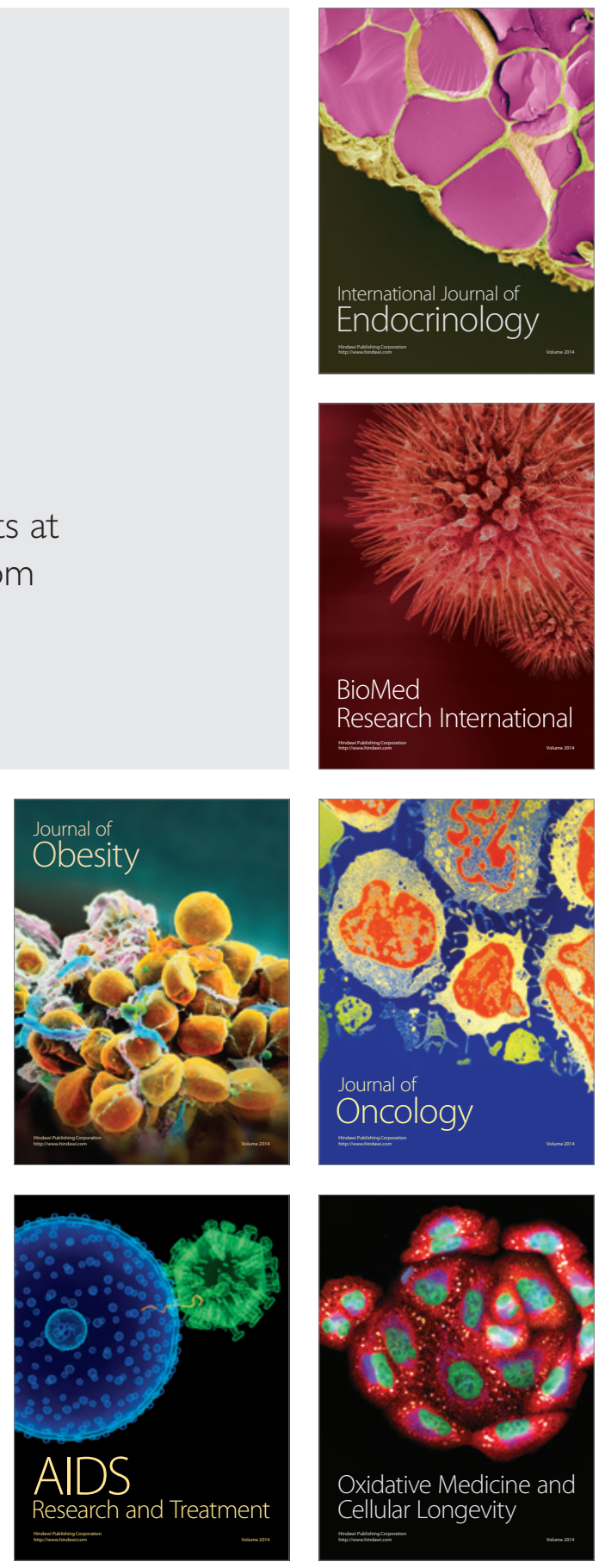